\title{
DESIGN OF ENERGY EFFICIENT STREET LIGHT FAULT MONITORING SYSTEM USING GSM NETWORKS
}

\author{
S. Hema \\ Assistant Professor, \\ Department of Electrical \\ and electronics \\ Engineering, Vel Tech, \\ Chennai, India,
}

\author{
V. Khaviya \\ UG Students, Department \\ of Electrical and \\ electronics Engineering, \\ Vel Tech, Chennai, India
}

\author{
P. Nivashini \\ UG Students, Department \\ of Electrical and \\ electronics Engineering, \\ Vel Tech, Chennai, India
}

\author{
K. Subhaanandhi \\ UG Students, Department \\ of Electrical and \\ electronics Engineering, \\ Vel Tech, Chennai, India
}

\begin{abstract}
Energy efficient lighting is designed to optimize the energy consumption for street lighting. This system aims to reduce energy consumption through designing a Smart lighting control system using a microcontroller. Lighting alone accounts for approximately $20 \%$ of the global electricity consumption of a day. In the current scenario, public lightings are usually turned on before the sunset and turned off after the sunrise where visibility is sufficient. Sensory network including infrared sensor, temperature sensor, light sensors are used for real time vehicular detection and light monitoring, programmable displays, alert system and a RTC dimming scheduling, notification and measurements are implemented. The microcontroller to governs the operations of the street Lighting system. Evaluation shows that it allows more energy and cost saving in street lighting.
\end{abstract}

\section{Keywords- Light Emitting Diodes, Street Lighting,} Microcontroller, sensors, GSM

\section{INTRODUCTION}

Street lighting is a public service provided by the government and sustained by public authorities at the local, state. Efficient lighting is vital for road safety, human safety and urban redecoration. Most street lights nowadays are manually operated despite several street lighting control technologies that have been developed .Proposed system is a cost effective automated street lighting control system which depends on a microcontroller based lighting management of the lamp posts activities of pedestrians, automotive traffic lighting conditions (Yin and Keoh, 2016). Developed a street light control system featuring three sensors-a LDR sensor, current sensor and a PIR sensor, and uses a PIC microcontroller to operate the lamps .The fault is detected using current sensor and the information is given to the prescribed number in electricity board. This system reduces the man power to a greater extent.

The high-pressure sodium vapor lamp has an average of $2000 \mathrm{k}$ colour temperature when compared to the LED streetlamp of $4000 \mathrm{~K}-6000 \mathrm{k}$ colour temperature (Lenk and Lenk, 2011). During lower colour temperature it gives an orange gleam appearance to HPS street-lighting but for LEDs, vast majority of its light is discharged downwards. As a result it minimize the wasteful reflections in the lighting fixture, giving a more uniform lighting on the ground and making it more contribute to pedestrian and road users. The life span of LED's module is $50,000 \mathrm{hrs}$ when compared to $5,000 \mathrm{hrs}$ of typical HPS, minimize the maintenance work cost in changing the light source. The LEDs drivers maintain the AC voltage to DC voltage and ensure a constant current to the LEDs module. Diagram 1 shows the connection of the LEDs driver which provides a DC supply to the LEDs modules and the PIC microcontroller which serves as the dimming device in this circuit. To supply dimming function to the LEDs module in the street lamp, pulse width modulation (PWM) is adopted with PIC microcontroller to provide digital pulse signal to switch on and switch off the LEDs module at a rate faster than our eyes can perceive (Mahadeokar and Sardeshmukh, 2015; Long et al., 2009).

\section{EXISTING SYSTEM}

Street light is poorly designed and not regularly maintained. The switches of street lights are switched ON/OFF manually by the workman in the entire zone. This leads to the rise of man power and time. As it is human operation it is lead to errors. The street lights are switched ON/OFF manually by the workman in all the zones. This leads to the rise of man power and time. As it is human operation it is prone to errors. There is a complaint register in every zonal office street light section. The maintenance of street light is done by the line technician. The complaint received from public and corporation officials either over phone is in person being recorded in the complaint register. The complaint which is entered is cleared by the technician (Schubert, 2016). 


\section{International Journal of Engineering Applied Sciences and Technology, 2020 \\ Vol. 4, Issue 12, ISSN No. 2455-2143, Pages 174-178 \\ Published Online April 2020 in IJEAST (http://www.ijeast.com)}

\section{PROPOSED SYSTEM}

Considerable low cost of maintenance. Energy conservation is important nowadays since there is a great demand towards electricity. Powered by a renewable supply of energy by solar panels there is no harmful atmosphere emissions and reducing light pollution. The lighting system works absolutely in the darkness, avoiding waste of energy. The sensors enable the system to operate absolutely when necessary. The system uses LED lamps to ensure correct illumination and assure energy savings. The selection of the battery depends on the conditions there the system is installed. The proposed system consumes low power, minimizing the battery capacity. Hence the health of street lamps is monitored by the current sensor. Instead of switching off thee lamps we control the intensity of lamp which reduces the maintainence of lamps as well as increases the life of lamps. This feature allows great energy conservation. In addition, any faulty lamp will be automatically turning OFF which avoid more energy wastage caused by faulty lamps. Because of this application of different illumination control on the system, the lamps are easily able to turn ON the lights with low illumination when the surrounding condition needs the low light illumination of the lamps. The road safety at night is increased by proposed effective street lighting system; It enhances the quality of lamp life for building by preventing crime and by making people feel more secure.

An energy saving feature is the ability to bleary all street lights in the night for traffic purpose. Intensity control can be adjusted according to date or special events, or light levels can be easily increased under perverse weather conditions or high traffic density to make travel safer. Intensity control reduces the costs by increasing lamp life, reduces man power costs belonging with frequent lamp replacement.

\section{WORKING PRINCIPLE}

\section{A. Fault detection}

The system is designed in such a way that in the street lights circuit we place light sensors and which are responsible to automatically on/off switching. Whenever the fault occur in the system it detected by sensors and this send signal to the microcontroller and with the help of GSM module attached with the circuit for sending message to the control station. With this information available in the control station, the technician can easily locate the particular light which reduces the time to identify it and repair it. The main objective of the proposed system is to accomplish individual faults repaired within less working hours instead of taking more time (Afshari et al., 2014).

The LDR module in the system is consists of two LDRs. One of the LDR is place over the street lamp for the identifying the day/night condition. Another LDR is used to monitor and checking the lamp health status which is place under the street lamp. The status of the lamp which is sense by the LDRs is send to microcontroller, where the microcontroller will process the information and send the data to the control station. The control station will monitor every street lamp status, also controlling the operation of the street lamps (Wang, 2014).

\section{B. Working}

The block diagram is given in fig A. The sensor block serves as an input to the microcontroller, which is also used for multiple applications such as motion detection, Light intensity indication or temperature measurement. The microcontroller receives data from the sensor and makes the decision based on the desired outcome programmed into the PIC microcontroller. It sends the instruction wirelessly to the driver of the LEDs modules at the street lamp (Alonso et al., 2012).

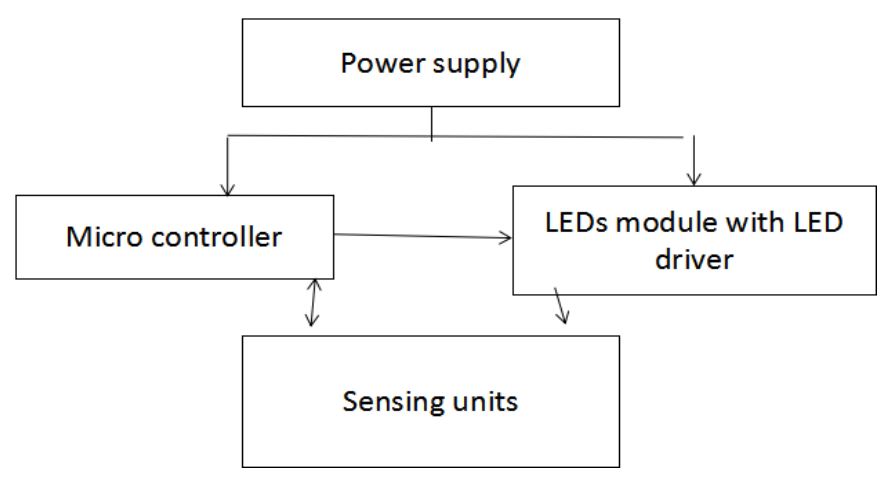

Figure 1 Components used in entire system

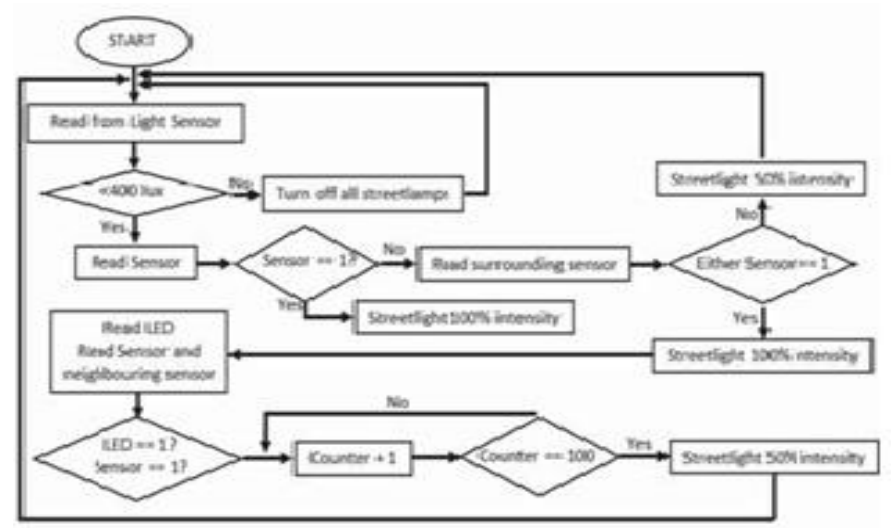

Figure 2 Flowchart for automatic working of energy efficient street lamp

This will raise the LEDs driver to either decrease its intensity or increase its light intensity by pulse width modulation. The controller of the public road regulator can also make adjustment to the sensing unit based on the data collected. The street lighting system will directly collects the 


\section{International Journal of Engineering Applied Sciences and Technology, 2020 \\ Vol. 4, Issue 12, ISSN No. 2455-2143, Pages 174-178 \\ Published Online April 2020 in IJEAST (http://www.ijeast.com)}

AC power from the power supply unit with the driver to covert the AC to DC voltage source to drive the LEDs (Liang et al., 2014).

The flow chart in Fig B is the efficient lighting system that lists the criteria for the adjustment of the LEDs street lamp intensity. The microcontroller checks if the light sensor value is above or below 400 lux to determine if the sun has already set. Once the lux level is below 400 lux, the system will start the operation. It now checks if a specific infrared sensor has detected any motion of vehicles or pedestrian. The microcontroller will immediately turn on that street light to operate at $100 \%$ intensity if $\mathrm{SENSOR}=1$, affirming the presence of traffic and loop back otherwise to read from Light sensor. After the system has turned on its street light to $100 \%$, it will now check if the vehicle is still in the vicinity via the neighboring infrared sensor. If it is affirmed to be positive, then the street lamp will continue to operate at $100 \%$ intensity. If not, it will activate a counter and count for a fixed period of time to reduce back to operating intensity at dimmed level, (at $50 \%$ of its full intensity).

\section{Prototype And Modes Of Operation}

Fig 3 shows the working model of the energy efficient street lamps

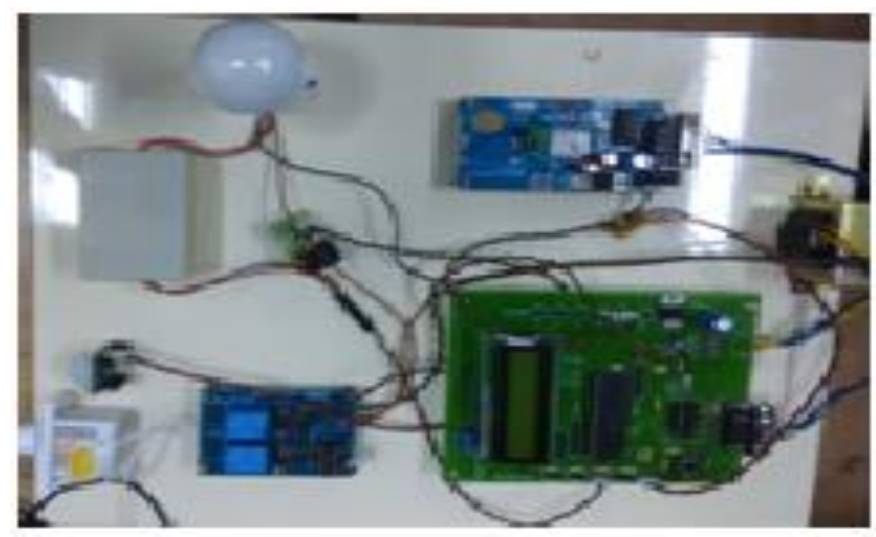

Figure 3 Energy efficient street lamps with fault detection using GSM module

When the infrared sensor picks up the moving vehicle, it activates the LED lighting around the detected street light as well as nearest street light to be lighted up at $100 \%$ intensity. In this scenario when the car has already gone past the street light for a period, the streetlight can be automatically dimmed to $50 \%$ light intensity or be switched off to save more electrical energy. There are two criteria for the streetlight to be switched off. First- The position of the infrared sensor and its nearby infrared sensors must not detect any motion. Secondlythe LEDs light modules has to be switched on initially. In this prototype, the streets light are programmed to switch off after
10 seconds after the two criteria have been met (Juan et al., 2016).

When the ambient light sensor detected that the ambient lighting is above 400lux, the Intelligent Lighting system will off all the LEDs.

\section{A. Dimming Schedule}

In this part, we proposed three types of dimming schedules which can be considered. These three modes of energy saving method are named as economic mode, intense mode and balanced mode. Each mode has a specific dimming schedule and is formulated based on the assumption that road users are minimal during certain hours during the night while the rest of the timing has a moderate and less amount of vehicular activity. The operating hours of a streetlamp throughout the year are calculated based on the lighting standards set by LTA as tabulated in Table I to maintain a minimal of 20 lux on the road for users. The time to switch on and off the streetlight is based on the local sunrise and sunset time at different period of the year. The time will be scheduled minimum with eight timing segments (Sureshet al., 2016; Morenoet al., 2017).

Table 1 The Different Segments For Eight Different Periods Of Time All Over The Year

\begin{tabular}{|c|c|c|c|c|}
\hline S/No & From & To & Time On & Time Off \\
\hline 1 & 10- Jan & 31-Mar & 1910 & 0721 \\
\hline 2 & 01-Apr & 17-Jun & 1903 & 0703 \\
\hline 3 & $18-$ Jun & 18-Aug & 1907 & 0711 \\
\hline 4 & $29-$ Aug & 15-Sep & 1859 & 0706 \\
\hline 5 & 16-Sep & 07-Oct & 1853 & 0701 \\
\hline 6 & 08-Oct & 06-Dec & 1847 & 0658 \\
\hline 7 & 07-Dec & 23-Dec & 1855 & 0707 \\
\hline 8 & 24-Dec & 19-Jan & 1903 & 0715 \\
\hline
\end{tabular}

The schedule is plotted from light intensity against its operating hour from Sunset till the time of Sunrise. During evening i.e., the time period of $7 \mathrm{pm}$ to $8 \mathrm{pm}$, for Economic Schedule, the operating duration is 0.83 hours since sunset happens at $7.10 \mathrm{pm}$ (based on Table I) and the Streetlight operates at $90 \%$ of full intensity (as in Fig 5a). Assuming the power rating of the lamp is $70 \mathrm{~W}$, the power consumption will be as calculated as follows:

Power usage $=0.83$ hours $* 90 \% * 70 \mathrm{~W}=52.29$ watt-hour

The process will be repeated till the time slot sunrise. The result of the expermentation is tabulated in a table. The total 


\section{International Journal of Engineering Applied Sciences and Technology, 2020 \\ Vol. 4, Issue 12, ISSN No. 2455-2143, Pages 174-178 \\ Published Online April 2020 in IJEAST (http://www.ijeast.com)}

amount of watt-hour accumulated throughout the entire day was multiplied by the total sum of days in the segment. Thereafter all 8 segments of power were added together to form the full amount of power usage over the year by operating them at the stated hours at scheduled dimmed value.

The calculation is done for all the 4 modes of dimming practices and the cost for the different schedules is as tabulated in Table II. The table also shows the information about power usage and cost of operating street lamp. Economic dimming seems to be the better illumination practice.

Table 2 Power Usage and Cost Of Operating A Street Lamp Per Annum

\begin{tabular}{|c|c|c|}
\hline Schedules & $\begin{array}{c}\text { Total Power Usage (kWh)/ } \\
\text { yearly }\end{array}$ & Cost (\$)/ yearly \\
\hline Economic Dimming & 209.8 & 44.87 \\
\hline $\begin{array}{c}\text { Intense Economic } \\
\text { Dimming }\end{array}$ & 256.4 & 54.84 \\
\hline Balance Dimming & 294.7 & 63.04 \\
\hline No Dimming & 335.6 & 71.78 \\
\hline
\end{tabular}

The results suggested that Economic Dimming schedule is advisable to be implemented especially for a stretched road which is in the sub-urban area and there is volume of traffic especially during the period from 12 midnight to $4 \mathrm{am}$. This can substantially reduce the energy consumption and cost incurred for street lighting considering that $126 \mathrm{kWh} /$ year of power can be saved for each street lamp.

\section{APPLICATIONS}

1. Street light fault detection.

2. Parking, malls, industries.

3. Home power control system.

4. Hospitals, Institutions/Organization.

5. Automatic switching of street light.

\section{FUTURE SCOPE}

The project has scope in different applications like providing lighting for offices, buildings, grounds, walking paths and parking garages of large shopping centres. This can also be utilized for security surveillance in corporate buildings, business centres, schools

\section{CONCLUSION}

The intelligent street lighting model has been successfully built and reveal the full capability of an actual lighting system.
The real time monitoring functions which includes operating dimming schedules with integrated advanced lighting for oncoming vehicle on the street, a programmable street signs to divert traffic or notify of important road condition and a light sensor that constantly tracks ambient lighting is incorporated. The system is fully equipped with multiple sensors are useful for data collection to understand the city's management needs and to perform preventive maintenance. The implementation of a micro controller with sensors in the intelligent lighting system for street lighting ensure that the adequate lighting is provided for all road users and at the same time optimizing the usage of our energy resources with the adoption of suitable dimming schedule based on volume of traffic at different time of the day and the different stretches of the road.

\section{REFERENCES}

1. Afshari, S., Mishra, S., Julius, A., Lizarralde, F., Wason, J., and Wen, J. (2014). Modeling And Control Of Color Tunable Lighting Systems. Energy And Buildings, 68, 242-253.

2. Alonso, J., Calleja, A., Gacio, D., Cardesin, J., and Lopez, E. (2011). A long-life high-power-factor HPSlamp LED retrofit converter based on the integrated buck-boost buck topology. IECON 2011 - 37Th Annual Conference Of The IEEE Industrial Electronics Society.

3. De Paz, J., Bajo, J., Rodríguez, S., Villarrubia, G., and Corchado, J. (2016). Intelligent system for lighting control in smart cities. Information Sciences, 372, 241255.

4. Lenk, R.,and Lenk, C. (2011). Practical Lighting Design With LEDs. Wiley-IEEE Press, 2011, 1-11.

5. Long, X., Liao, R., and Zhou, J. (2009). Development of street lighting system-based novel high-brightness LED modules. IET optoelectronics, 3(1), 40-46.

6. Mahadeokar, S., and Sardeshmukh, M. (2015). Energy efficient PWM Dimmable Smart Digital LED driver. In 2015 International Conference on Energy Systems and Applications (pp. 306-311).

7. Moreno, M., Terroso-Saenz, F., Gonzalez-Vidal, A., Valdes-Vela, M., Skarmeta, A., Zamora, M., and Chang, V. (2017). Applicability of Big Data Techniques to Smart Cities Deployments. IEEE Transactions On Industrial Informatics, 13(2), 800-809.

8. Schubert, E. (2006). Light-Emitting Diodes. Cambridge: Cambridge University Press.

9. Suresh S., Anusha, H., Rajath, T., Soundarya, P., and Vudatha, S. (2016). Automatic lighting and Control System For Classroom. 2016 International Conference On ICT In Business Industry and Government (ICTBIG).

10. Wang, R. (2014). Choice on Control System Technology of Intelligent Lighting,.. Electrical and Intelligent Building, 1-2, 79-81. 
11. Yansong Liang, Zhouding Jia, Huanzhong Yao, and Jing Chen. (2014). Housing intelligent lighting control strategy research. 2014 IEEE 3Rd International Conference On Cloud Computing And Intelligence Systems, (pp. 728-731)

12. Yin, X., and Keoh, S. (2016). Personalized ambience: An integration of learning model and intelligent lighting control. 2016 IEEE 3Rd World Forum On Internet Of Things (WF-Iot). 